\title{
Self - Medication of Anti-microbial Agents (AMAs) and Over-the-Counter Practices: A Study in Mymensingh Sadar Area
}

\author{
Begum $\mathrm{SA}^{1}$, Hasan $\mathrm{MJ}^{2}$, Sharmeen $\mathrm{A}^{3}$, Sultana $\mathrm{S}^{4}$
}

\begin{abstract}
Self-medication is common in countries where prescription legislations are not strong enough and drugs are available over the counter. This study was conducted to assess the self-medication by antibiotics in Mymensingh Sadar Area population and determine the factors related to it. This descriptive study was conducted in Mymensingh Sadar Area between January 2010 and December 2010. Convenient sampling was used to select respondents from among those who came to the community pharmacies to purchase drugs for self-medication. Respondents were interviewed after they made their requests but before they were provided with information on the drugs they requested. Data were collected using structured questionnaire. Drug consumers consisted of all age categories of both genders; as well as different occupations of varying educational background levels. The most frequently reported illnesses that prompted self-medication of respondents were fever, dental pain, cough \& common cold, dermatological and ENT problems. Over $42 \%$ of them made their requests by telling symptoms of illness and $32.3 \%$ obtained advice from traditional healers. The most common reasons reported for self-diagnosis and self-medication were cost of physician service and non-seriousness of the disease. More than 13 different types of antibiotics were requested, the most frequent category of antibiotics being ciprofloxacin/other FQS $21 \%$, amoxicillin $16.5 \%$, azithromycin/erythromycin $14 \%$ and cephalosporin $13.3 \%$. Self-medication is widely practiced for a wide range of illnesses or symptoms of illnesses and for over-the-counter. The public as well as the health care providers have to be educated on the scopes of self-medication; i.e., the type of illnesses to be self-diagnosed and self-treated and the type of drug products to be used in order to promote responsible self-medication.
\end{abstract}

CBMJ 2013 Jan: Vol 02, No 01: P: 15-20

Key words: Self-medication, Self-diagnosis, Drug consumers, Antibiotics..

\section{Introduction}

Medication refers to the act of consuming medicines for prevention, diagnosis or treatment of diseases. Correct medication is observed by reporting any symptom or disease to the physician in the hospital or clinic who diagnoses and prescribes the needed drugs to alleviate the condition. This is usually followed by filling of such prescriptions at the pharmacy by the pharmacist ${ }^{1}$. Self-medication can be defined as the use of drugs to treat self-diagnosed disorders or symptoms or the intermittent or continued use of a prescribed drug for chronic or recurrent disease or symptoms. Over-the counter drugs are a form of self medication. The buyer diagnoses his own illness and buys a specific drug to treat it. ${ }^{2}$
1. * Dr. Shamim Ara Begum Associate Professor (C.C), Department of Pharmacology ,Community Based Medical College Bangladesh.

2. Dr. Mahmud Javed Hasan Assistant Professor, Department of Nephrology, Community Based Medical College Bangladesh.

3. Dr. Atia Sharmeen Medical Officer, Department of Dermatology \& VD, Community Based Medical College Bangladesh.

4. Dr. Shamima Sultana Assistant Professor of Pharmacology, Mymensingh Medical College.

\footnotetext{
* Address of correspondence

E-mail:shamimdr68@gmail.com Mobile: +8801729431833
} 
Original Article

A large number of people, when they fall sick, do not consult the physician. They either consult a drug store and obtain a medicine from the shelf or may consult a neighbour who may be having some tablets left over from his previous illness and readily spares them. ${ }^{3}$ A major shortfall of self-medication is the lack of clinical evaluation of the condition by a trained medical professional, which could result in missed diagnosis and delays in appropriate treatments. ${ }^{4}$ A major problem with self-medication with antimicrobials is the emergence of human pathogens resistance. Self-medication with antibiotics is of serious medical concern. Antimicrobials resistance is a current problem world-wide particularly in developing countries, where antibiotics are often available without a prescription. ${ }^{5}$ The important public health threat of antibiotic resistance depends on antibiotic overuse/misuse.

Self-care is a predominant therapeutic activity consisting $30-40 \%$ of the disadvantaged populations including women, elderly, ethnic minorities and poor in Bangladesh. ${ }^{6}$ Selfmedication as a mean of self-care through the purchase of over-the-counter (OTC) medicines is, and always has been common in the society for a wide variety of minor ailments, such as headaches, colds and indigestion. But such products can often be misused or abused. ${ }^{7}$ Over-the-counter medicines have emerged as drugs of serious misuse across Bangladesh, and other neighbouring countries. One report estimates that there are 4 million drug misusers in the South Asian region, where Bangladesh accounts for half a million of the total. ${ }^{8}$ Along with the common practices of self medication, almost every drug store salesperson is illegally involved in the recommendation and sells of prescription only medicines in Bangladesh. ${ }^{9}$ Self-medications in a country with low literacy level like Bangladesh is very important where prescription medicines are freely available. This may pose serious risks related to inappropriate and irrational personal use of medicines. Some sporadic studies reported awful self-medication behaviours among general populations in Bangladesh. Therefore, the present study was undertaken to assess the self-medication by antibiotics in Mymensingh Sadar Area population and determine the factors related to it.

\section{Methods:}

A community-based, descriptive study was conducted at community pharmacy center in Mymensingh Sadar Area in January 2010 and December 2010. Because of the absence of relevant data, we estimated a sample size of approximately 400 for an assumed prevalence of self-medication of $50 \%$, a $95 \%$ confidence level and a $5 \%$ margin of error. These patients were asked to answer an anonymous questionnaire regarding their use of medicine in the twelve months preceding the present illness. Selection of the participants was based on convenient sampling from amongst all the patients; every visitor was chosen and verbal consent obtained after briefing them on the objectives of the study. The choice of medications was made either by the patient or selected by the community pharmacist. Those patients were asked to verbally answer a 54-item questionnaire that include questions about age, sex, monthly income, level of education, occupation, illness among patients seeking for self medications, type of request for self medication by drug consumers, source of advice for self-medication by drug consumers, factor influencing of self medication and pattern of various antibiotics used were also noted. The survey data were checked, coded and entered into a SPSS statistical package (Version 11.5). The data were then cleaned and analyzed using descriptive statistics were used to determine frequency of the responses and shown as mean $\pm \mathrm{SD}$.

\section{Results:}

An analysis of the results showed that of the 400 respondents surveyed, majority of them were male $(75.8 \%)$. The male to female ratio was 3.1:1 and the mean age was age $37.5 \pm$ 0.4 years. Over $40 \%$ of customers had monthly income less than Taka 10000, 43.6\% between $10000-20000$ and $15.2 \%$ more than Taka 20000. The mean monthly income was Taka 10469.8 \pm 385.7 . A higher proportion of customers was HSC and graduate \& above level educated and students were predominant who came to purchase drugs 
Original Article

(without prescriptions) for self-medication (Table I).

Frequently reported illnesses or symptoms of illnesses that prompted respondents for selfmedication as shown in Table II, were 1.3\% headache, $9.3 \%$ dental pain, $6 \%$ muscle \& joint pain, $9.8 \%$ cough \& common cold, $5.3 \%$ gynecology \& contraceptive problem, $7.3 \%$ dermatological problems, $3.5 \%$ opthalmic conditions, $5.5 \%$ urinary tract infection, $0.5 \%$ general weakness, $5 \%$ acute watery diarrhea, $4.5 \%$ acute trauma, $1.3 \%$ oedema, $5.5 \%$ asthma \& others COPD, $12.5 \%$ fever, $4.8 \%$ ameobiasis, $7.5 \%$ dysentery, $8.8 \%$ ENT problem, $1.3 \%$ oral thrust and $2.5 \%$ burn.

Asked about type of requests for selfmedication, $18.8 \%$ of them made their requests by mentioning specific names of the drugs or drug products, $42.3 \%$ of the drug consumers told their symptoms to the persons who stood behind the counter in the pharmacies, $0.5 \%$ of the respondents requested drugs by mentioning the category of drugs, $12.5 \%$ of the drug consumers were requesting drugs by showing old samples or packages of drug products, $24.8 \%$ presenting piece of paper (not a prescription) and 1.1\% described physical characteristics of drug (Table III).

In the present study, nearly one-quarter (23.5\%) of drug consumers reported that they obtained advice from health care providers but without formal prescriptions, $26.3 \%$ of them said they were advised by friends, relatives or neighbours, who themselves had no background in the health profession. About $15 \%$ of customers requested OTC drugs of the advice of pharmacists or other personnel working in pharmacies, $0.8 \%$ read material and $32.3 \%$ received advice from traditional healers (Table IV).

Asked as to why they resort to self-diagnosis and self-medication, a large proportion of respondents replied that cost of physicians service. About $20 \%$ of them opinion that disease is not serious, $13.5 \%$ complaints excess unnecessary lab investigations, 9.5\% lack of time, $7 \%$ lack of truthful physician and $1 \%$ of the respondents requested drugs for familiar with disease \& its remedy (Figure 1).
Drug consumers were also asked or observed on the types of drugs they request for selfmedication. More than 13 different types of drugs or category of drugs were requested, $9.3 \%$ of the drug consumers mentioned PenV, $6.5 \%$ Cloxacillin/ Flucloxacillin, $13.3 \%$ Cephalosporin, $16.5 \%$ amoxicillin, $21 \%$ ciprofloxacin/other $\quad$ FQS, $\quad 12.8 \%$ metronidazole, $\quad 14 \%$ azithromycin/ erythromycin, $1 \%$ cotrimoxazole, $1.3 \%$ doxycycline/ Tetracycline, 2\% albendazole/ mebendazole, $5 \%$ azole antifungal drugs, $6.3 \%$ gentamycin/ neomycin and another $1 \%$ chloramphenicol (Table V).

Table I: Socio-demographic characteristics of drug consumers $(n=400)$

\begin{tabular}{|c|c|c|}
\hline $\begin{array}{l}\text { Socio-demographic } \\
\text { characteristics }\end{array}$ & Frequency & Percentage \\
\hline \multicolumn{3}{|l|}{ Age (years) } \\
\hline$<30$ & 59 & 14.8 \\
\hline $30-40$ & 132 & 33.0 \\
\hline $40-50$ & 168 & 42.0 \\
\hline$\geq 50$ & 41 & 10.3 \\
\hline \multicolumn{3}{|l|}{ Sex } \\
\hline Male & 303 & 75.8 \\
\hline Female & 97 & 24.3 \\
\hline \multicolumn{3}{|l|}{$\begin{array}{l}\text { Monthly income } \\
\text { (Taka) }(\mathrm{n}=303)\end{array}$} \\
\hline$<10000$ & 125 & 41.3 \\
\hline $10000-20000$ & 132 & 43.6 \\
\hline$>20000$ & 46 & 15.2 \\
\hline \multicolumn{3}{|l|}{ Educational level } \\
\hline Illiterate & 74 & 18.5 \\
\hline Read and write & 58 & 14.5 \\
\hline Below SSC & 43 & 10.8 \\
\hline SSC & 45 & 11.3 \\
\hline HSC & 90 & 22.5 \\
\hline Graduate \& above & 90 & 22.5 \\
\hline \multicolumn{3}{|l|}{ Occupation } \\
\hline Housewife & 54 & 13.5 \\
\hline Service & 79 & 19.7 \\
\hline Business & 95 & 23.7 \\
\hline Farmer & 43 & 10.8 \\
\hline Student & 129 & 32.3 \\
\hline
\end{tabular}


Original Article

Table II: Illness among patients seeking for self medications $(n=400)$

\begin{tabular}{|l|c|c|}
\hline Illness & Frequency & Percentage \\
\hline Headache & 05 & 1.3 \\
\hline Dental pain & 37 & 9.3 \\
\hline Muscle \& joint pain & 24 & 6.0 \\
\hline Cough \& common cold & 39 & 9.8 \\
\hline $\begin{array}{l}\text { Gynecology \& } \\
\text { contraceptive problem }\end{array}$ & 21 & 5.3 \\
\hline $\begin{array}{l}\text { Dermatological } \\
\text { problems }\end{array}$ & 29 & 7.3 \\
\hline Opthalmic conditions & 14 & 3.5 \\
\hline Urinary tract infection & 22 & 5.5 \\
\hline General weakness & 02 & 0.5 \\
\hline Acute watery diarrhea & 20 & 5.0 \\
\hline Acute trauma & 18 & 4.5 \\
\hline Oedema & 05 & 1.3 \\
\hline $\begin{array}{l}\text { Asthma \& others } \\
\text { COPD }\end{array}$ & 22 & 5.5 \\
\hline Fever & 50 & 12.5 \\
\hline Ameobiasis & 19 & 4.8 \\
\hline Dysentry & 30 & 7.5 \\
\hline ENT problem & 35 & 8.8 \\
\hline Oral thrust & 05 & 1.3 \\
\hline Burn & 10 & 2.5 \\
\hline
\end{tabular}

Table III: Types of requests for self-medication by drug consumers $(n=400)$

\begin{tabular}{|l|c|c|}
\hline \multicolumn{1}{|c|}{$\begin{array}{c}\text { Self-medication by } \\
\text { drug consumers }\end{array}$} & Frequency & Percentage \\
\hline Mention name of drug & 75 & 18.8 \\
\hline $\begin{array}{l}\text { Telling symptoms of } \\
\text { illness }\end{array}$ & 169 & 42.3 \\
\hline $\begin{array}{l}\text { Mentioning category of } \\
\text { drug }\end{array}$ & 02 & 0.5 \\
\hline $\begin{array}{l}\text { Showing old } \\
\text { sample/package of drug }\end{array}$ & 50 & 12.5 \\
\hline $\begin{array}{l}\text { Presenting piece of } \\
\text { paper (not a } \\
\text { prescription) }\end{array}$ & 99 & 24.8 \\
\hline $\begin{array}{l}\text { Describing physical } \\
\text { characteristics of drug }\end{array}$ & 05 & 1.1 \\
\hline
\end{tabular}

Table IV: Sources of advice for self-medication by drug consumers $(n=400)$

\begin{tabular}{|l|c|c|}
\hline $\begin{array}{l}\text { Sources of advice for } \\
\text { self-medication }\end{array}$ & Frequency & Percentage \\
\hline $\begin{array}{l}\text { Advised by health care } \\
\text { providers but without } \\
\text { prescription }\end{array}$ & 94 & 23.5 \\
\hline $\begin{array}{l}\text { Advised by } \\
\text { friends/relatives/ } \\
\text { neighbors }\end{array}$ & 105 & 26.3 \\
\hline $\begin{array}{l}\text { Pharmacist or working } \\
\text { in pharmacy }\end{array}$ & 61 & 15.3 \\
\hline Read materials & 03 & 0.8 \\
\hline $\begin{array}{l}\text { Advice from traditional } \\
\text { healers }\end{array}$ & 129 & 32.3 \\
\hline
\end{tabular}

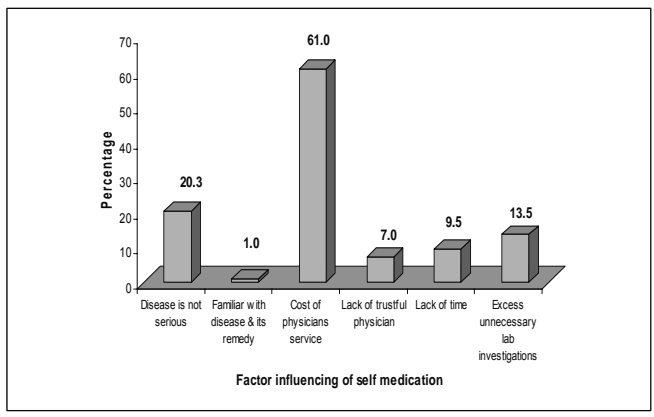

Fig.1: Factor influencing of self medication $(n=400)$

Table V: Pattern of various antibiotics $(n=400)$

\begin{tabular}{|l|c|c|}
\hline \multicolumn{1}{|c|}{$\begin{array}{c}\text { Pattern of various } \\
\text { antibiotics }\end{array}$} & $\begin{array}{c}\text { Freque } \\
\text { ncy }\end{array}$ & Percentage \\
\hline Pen-V & 37 & 9.3 \\
\hline Cloxacillin/Flucloxacillin & 26 & 6.5 \\
\hline Cephalosporin & 53 & 13.3 \\
\hline Amoxycillin & 66 & 16.5 \\
\hline Ciprofloxacin/other FQS & 84 & 21.0 \\
\hline Metronidazole & 51 & 12.8 \\
\hline Azithromycin/Erythromycin & 56 & 14.0 \\
\hline Cotrimoxazole & 04 & 1.0 \\
\hline Doxycycline/Tetracycline & 05 & 1.3 \\
\hline Albendazole/Mebendazole & 08 & 2.0 \\
\hline Azole antifungal drugs & 20 & 5.0 \\
\hline Gentamycin/Neomycin & 25 & 6.3 \\
\hline Chloramphenicol & 04 & 1.0 \\
\hline
\end{tabular}

${ }^{*}$ Multiple responses 


\section{Discussion}

The present study highlights the problem of self-medication with antibiotics as OTC (Over the Counter) at Mymensingh Sadar Area. In both developed and developing countries, self-medication with antibiotics is common for illnesses. However, the methods used in the present study make it possible to document that the prevalence of non-prescription use of antibiotics for customers. Our study confirms age played a role in the issue of self medication among the patients. The major factors associated with self medication with antibiotics is assumed knowledge on diseases and their treatments, financial status, advised by friends/relatives/neighbors, advice from traditional healers, cost of physicians service, excess unnecessary lab investigations, lack of time and "unseriousness" of the nature of illness. Studies in Spain and Nepal ${ }^{10,11}$ showed a tendency for undesirable self medication with respondents 40 years of age and below, respondents who live alone or students than other groups of people. Self medication in general is quite high even in the educated class of different countries. In different studies it is $45 \%$ in Turkey, ${ }^{12} 1494 \%$ in Hong Kong ${ }^{13}$ and $88 \%$ in Croatia. ${ }^{14}$ Our study is on the rural population and such a high prevalence was found in illiterate, HSC and graduate \& above level educated adult respondents.

According to respondents, about $9 \%$ of the drug consumers mentioned Pen- $\mathrm{V}, 6.5 \%$ cloxacillin/Flucloxacillin, $13.3 \%$ cephalosporin, $16.5 \%$ amoxicillin, $21 \%$ ciprofloxacin/other FQS, $\quad 12.8 \%$ metronodazole, $14 \%$ azithromycin/erythromycin, $1 \%$ cotrimoxazole, $1.3 \%$ doxycycline/tetracycline, $2 \%$ albendazole/mebendazole, $\quad 5 \%$ azole antifungal drugs, $6.3 \%$ gentamycin/neomycin and another $1 \%$ chproamhnocol. This rate is very high compared with results conducted in Jordan $(23 \%)$, and lithuania $(39.9 \%) .^{15,16}$ The self use of antibiotics is also very common in Sudan $(48 \%)^{17}$ while it is not very high in our neighborhood India where it has been quoted as $18 \% .{ }^{18}$ In a study conducted in Pakistan, the prevalence of self medication among university students was $76 \%{ }^{19}$ This study conducted in Karachi had almost similar results to ours in certain areas. The most common symptoms were headache $(72.4 \%)$ and fever (55.2\%) against ours $1.3 \%$ and $12.5 \%$. The difference between the symptoms was probably due to the fact that our study was conducted exclusively on the use of antibiotics while that study was conducted on self-medication of any drug. Our results also comparable to those of rural population in Greece were amoxicillin (18.3\%), amoxicillin/clavulanic acid (15.4\%), cefaclor $(9.7 \%)$, cefuroxim $(7.9 \%)$, cefprozil $(4.7 \%)$ and ciprofloxacin (2.3\%). Fever (41.2\%), common cold $(32.0 \%)$ and sore throat $(20.6 \%)$ were the most frequent indications for their use. ${ }^{20} \mathrm{~A}$ recent study in Pakistan reported that the antibiotic most frequently used were amoxicillin/clavulanic acid $(45 \%)$, ciprofloxacin $(31 \%)$, sulfamethoxazole/trimethoprim (18\%), and clarithromycin (5\%). Fever $(70 \%)$, sore throat $(22 \%)$ and common cold $(8 \%)$ were the symptoms for self medication. High cost of health care was mentioned the reason for self-medication by majority ( $88 \%)$. Majority $(82 \%)$ thought fever, sore throat and common cold as trivial illnesses controllable with selfmedication. ${ }^{21}$ It should be noted here that although acute and minor illnesses can be treated with appropriate self-medication, serious and longer duration of illnesses should get the attention of appropriate health care providers. On the other hand, drug consumers told their symptoms or complaints to the dispenser lending themselves to the care of the "pharmacist" to play their role as drug use educators and counsellors. Although the latter type of practice should be encouraged, much effort is required to advise/counsel or educate drug consumers in general and in particular those who request specific drugs or category of drugs as well as those who present old samples/ packages or pieces of paper for self-medication.

\section{Conclusion:}

From the results it is apparent that selfmedication is widely practiced by people of all age groups in the community of Mymensingh Sadar Area, despite good access to health care facilities adult population resorts to the use of antibiotics without a prescription for various reasons. The study has also revealed that the type of self-diagnosed illnesses/symptoms of illnesses and the category of drugs requested for self- 
medication are extensive. Pharmacy staff behavior can be a factor that puts patients at risk for self-medication with antibiotics. Community pharmacies are failing their tasks in enhancing rational use of antibiotics. Such a practice may be a consequence of weak enforcement and control over the legislation and professional standards. We propose additional studies at other primary health care units situated in other parts Bangladesh to make generalisable conclusions for the whole country.

\section{References}

1. Femi-Oyewo, MN, Adejumo OE \& Hassan SA. Self-medication Pattern among Students of Olabisi Onabanjo University, Ogun State. Nig. J. Pharm. 2002;1(1):17-20.

2. WHO, 2001. Guidelines for the regulatory assessment of medicinal products for use in self-medication.WHO/EDM/QSM/00.1.

3. Barar FSK, 2005. Dangers of Self-Medication. Available at:www.boloji.com.

4. Hamel MJ, Odhacha A \& Roberts JM. Malaria control in Bungoma District, Kenya: A survey of home treatment of children with fever, bednet use and attendance at antenatal clinics. Bulletin of the World Health Organization 2001;79:1014-23.

5. Chalker J. Improving antibiotic prescribing in Hai Phong Province, Viet Nam: he "antibioticdose" indicator. Bulletin of the World Health Organization 2001;79(4).

6. Ahmed SM. Exploring Health-seeking behaviour of disadvantaged populations in rural Bangladesh (PhD Dissertation, No. 05/433). Karolinska University Press 2005, Sweden. Available from: http://diss.kib.ki.se/2005/91-7140-435-X/.

7. Wazaify $M$, Shields $E$, Hughes $C M \& M c E l n a y$ JC. Societal perspectives on over-the-counter (OTC) medicines. Family Practice 2005;22(2):170-76.

8. Mudur G. Abuse of OTC drugs rising in South Asia. BMJ 1999;318:556.

9. Roy J. Health status, treatment and drug use in rural Bangladesh: a case study of a village. Ausralian Journal of Rural Health 1997; 5(2):70-5.

10. Figueiras $A$, Caamano $F$ \& Gestal-Otero J. Sociodemographic factors related to selfmedication in Spain. Eur $\mathrm{J}$ Epidemiol 2000;16(1):19-26.

11. Shankar PR, Partha $P \&$ Shenoy $N$. Selfmedication and non-doctor prescription practices in Pokhara valley, Western Nepal: a questionnaire-based study. BMC Fam Pract 2002;3:17.

12. Buke C, Limoncu M, Ermevtcan S, Ciceklioglu $M$, Tuncel $M$, Kose $T$, et al, Irrational use of antibiotics among university students. J Infect 2005;51:135-9.

13. Lau GS, Lee KK \& Luk CT. Self-medication among university students in Hong Kong. Asia Pac J Public Health 1995;8:153-7.

14. Vucic VA, Trkulja V \& Lackovic Z. Content of home pharmacies and self-medication practices in households of pharmacy and medical students in Zagreb, Croatia: findings in 2001 with a reference to 1977. Croat Med J 2005;46:74-80.

15. Al-Azzam SI, Al-Husein BA, Alzoubi $F$, Masadeh MM \& Al-Horani S. Self-medication with antibiotics in Jordanian Population. Int $\mathrm{J}$ Occup Med Environ Health 2007;20;373-80.

16. Berzanskyte $A$, Valinteliene $R$, HaaijerRuskamp FM, Gurevicius $R$ \& Grigoryan $L$. Self-medication with antibiotics in Lithuania. Int J Occup Med Environ Health 2006;19:24653.

17. Awad A, Eltayeb I, Matowe $L$ \& Thalib L. Selfmedication with antibiotics and antimalarials in the community of Khartoum State, Sudan. J Pharm Pharm Sci 2005;12; 8:326-31.

18. Saradamma RD, Higginbotham $N$ \& Nichter $M$. Social factors influencing the acquisition of antibiotics without prescription in Kerala State, south India. Social Science and Medicine 2000:50;891-903.

19. Zafar SN, Syed $R$, Waqar $S$, Zubairi AJ, WHYPERLINK

"http://www.pakmedinet.com/author/Talha+Va qar"aqar $T$, Shaikh $M$, et al. Selfmedication amongst university students of Karachi: prevalence, knowledge and attitudes. J Pak Med Assoc 2008;58:214-7.

20. Eystathios S, Panagiotis $M$, Athanasia $P$, Aristofanis $G$, George $M$, Christos $P$ \& Ioannis $T$ et al. Self-medication with antibiotics in rural population in Greece: a cross-sectional multicenter study. BMC Family Practice 2010;11:58.

21. Khan SJ, Amanullah, Khan S \& Shah N. Selfmedication with antibiotics in urban areas of peshawar. Gomal Journal of Medical Sciences 2011; 9(1):1-4. 